\title{
PENENTUAN HARGA PADA JARINGAN INTERKONEKSI TELEKOMUNIKASI: Sebuah Studi Pustaka
}

\author{
Eko Atmadji \\ Pascasarjana Fakutlas Ekonomi Universitas Islam Indonesia \\ e-mail: ekoatmadji@gmail.com
}

\begin{abstract}
The one which influences the price of telecommunication services is interconnection fee. In accordance with interconnection fee, the price determination depends on the types of competition. In symmetric competition and linear pricing, the price would be high because of the penchant of collusion and interconnection fee should be high. The opposite results occur when non linear pricing (two part tariff) is applied because all companies set the interconnection fee close to marginal cost. In asymmetric competition, the price tends to be low. However, the lowness of price caused by the application of predatory pricing by incumbent company and interconnection fee equals with marginal cost. After the entrants were expelled, the price will be higher. The government regulation toward interconnection fee could not be determined because it depends on the types of competition and the pricing linearity.
\end{abstract}

Keywords: telecommunication, interconnection fee, competition, two part tariff

\section{PENDAHULUAN}

Jaringan interkoneksi adalah merupakan suatu skema industri yang melibatkan beberapa perusahaan di mana perusahaanperusahaan tersebut harus menerima permintaan pesaingnya untuk menggunakan jaringan yang dimilikinya. Industri yang dimaksud adalah industri jaringan (network industry) dimana seorang konsumen merasa mendapat manfaat dari transaksinya karena ada konsumen lain yang juga menggunakan jaringan tersebut (Shy, 2001). Untuk dapat menggunakan jaringan milik pesaingnya maka suatu perusahaan harus membayar sejumlah tarif atau fee tertentu. Di samping itu, karena nantinya jaringan perusahaan tersebut juga akan digunakan oleh pesaingnya, maka ia juga berhak menentukan fee kepada pesaingnya untuk masuk jaringan.

Contoh dari industri jaringan ini adalah pos, kereta api di Eropa, perbankan, dan telekomunikasi. Interkoneksi pos terjadi pada pengiriman surat antar negara dimana tiap-tiap negara dimonopoli oleh perusahaan pos nasional. Kereta api di Eropa juga dibebani masalah interkoneksi ketika jaringan kereta api seluruh Eropa yang dimiliki oleh masing-masing negara terhubungkan sehingga memungkinkan seseorang melakukan perjalanan dari Paris ke Bonn tanpa perlu mengalami kerepotan beli karcis berkali-kali dan pindah kereta. Bagi bisnis perbankan, interkoneksi terjadi pada pengiriman uang dari seorang nasabah di suatu bank ke nasabah pada bank lain. Melalui mekanisme kliring sebagai cara melakukan interkoneksi, proses pengiriman uang menjadi terlaksana dan aman. Interkoneksi telekomunikasi terjadi ketika A menghubungi B di luar negeri melalui jaringan telepun. Perusahaan jasa telepun yang dilanggan A akan menghubungi perusahaan jasa telepun negara domisili B untuk menggunakan jaringannya agar dapat menghubungi $\mathrm{B}$.

Dari kelima contoh tersebut kasus telekomunikasi yang paling banyak literatur risetnya. Hal itu dikarenakan bisnis di bidang telekomunikasi secara ekonomi menjadi semakin penting karena sifatnya yang membawa informasi. Di 
samping itu, bisnis ini memiliki jaringan paling rumit dibanding keempat industri lainnya. Bagi industri telekomunikasi, jaringan interkoneksi meliputi berbagai produk seperti telepun, internet, telepun seluler, satelit, dan lain-lain.

Salah satu persoalan yang penting dalam masalah jaringan interkoneksi adalah dalam penentuan harga. Harga yang dimaksud adalah harga yang harus dibebankan kepada konsumen dan fee interkoneksi antar operator telekomunikasi. Harga pada konsumen atau pengguna akhir telekomunikasi tergantung dari skedul permintaan dan penawaran pasar. Sedangkan pada fee interkoneksi, ada dua kondisi yang mempengaruhi fee interkoneksi tersebut. Pertama, kondisi kesimetrisan jaringan. Kondisi jaringan yang simetris adalah perusahaan-perusahaan yang berkaitan memiliki kekuatan pasar yang sama. Dalam bernegosiasi harga, mereka akan cenderung menerapkan tarif yang sama. Pada kondisi jaringan yang tidak simetris (asimetris) terdapat perusahaan dominan yang telah lama ada (incumbent) dan perusahaan-perusahaan yang baru masuk (entrants). Perusahaan lama sebelumnya menikmati monopoli jaringan yang diberikan negara yang kemudian dilepas haknya dan harus bersaing dengan perusahaan-perusahaan baru. Dalam persaingan jenis ini, perusahaan lama cenderung menerapkan strategi predatory pricing agar kekuasaan monopoli dapat kembali lagi. Kedua, kondisi campur tangan pemerintah. Ada berbagai pilihan yang bisa dilakukan pemerintah dalam campur tangan industri jaringan agar tercapai kondisi kemakmuran yang tinggi seperti pengaturan pada industri hulunya saja atau hilirnya saja.

Tulisan ini merupakan sebuah studi pustaka tentang penentuan harga pada hubungan interkoneksi antar perusahaan jaringan dalam industri telekomunikasi. Pada bagian berikut akan dibahas tentang penentuan harga dalam per- saingan yang simetris yaitu dari penentuan harga linier dan penentuan harga non linier. Pada bagian ketiga akan dibahas pula persaingan dalam persaingan yang asimetris. Pada bagian keempat akan membahas dampak campur tangan pemerintah dalam penentuan harga interkoneksitas pada kesejahteraan masyarakat (social welfare). Tulisan ini hanya akan membahas penentuan harga layanan akhir telekomunikasi yang tunggal dimana harga layanan ini sama untuk semua koneksi antar pelanggan suatu perusahaan maupun pelanggan dari perusahaan pesaingnya. Diskriminasi hargal layanan telekomunikasi didiskusikan secara ekstensif oleh Laffont et. al (1998b).

\section{PENENTUAN HARGA INTERKONEKSI DALAM PERSAINGAN SIMETRIS}

Dalam persaingan yang simetris diasumsikan bahwa jumlah pelanggan tetap, pelanggan akan memilih operator yang terdekat dengan tempat tinggalnya, dan struktur ongkos dianggap sama (Laffont et. al, 1998a, selanjutnya disebut LRT). Contoh yang terdekat dari asumsi ini adalah layanan telepun antar negara yang setara, dimana status negara kaya dan miskin menjadi penting. Pelanggan telepun tersebut adalah pengguna jasa perusahaan telepun di negaranya. Contoh mutakhir dari asumsi ini meskipun diperlukan sedikit modifikasi adalah pasar telepun seluler. Ketika seseorang memilih operator tertentu cenderung akan tetap setia dan sulit untuk berpindah operator Pilihan awal sebuah operator dikarenakan adanya pengaruh dari lingkungannnya.

Menurut LRT (1998a), dalam persaingan antar operator yang linier, ekuilibrium harga jual jasa telekomunikasi

\footnotetext{
1 Tarif koneksi antar pengguna akhir perusahaan A lebih rendah daripada koneksi pengguna akhir perusahaan B ke pengguna akhir perusahaan A.

2 Dalam rangka menghindari kerepotan teman atau rekannya mengganti catatan nomer telpun selulernya secara terus menerus.
} 
pada pengguna akhir tergantung pada dua hal yaitu derajat substitusi antara jasa operator dan tarif interkoneksi antar operator. Derajat substitusi yang dimaksud adalah seberapa besar kemampuan saling mengganti dari jasa tiap perusahaan telekomunikasi. B Derajat substitusi terlalu besar akan membuat pasar dalam kondisi kompetisi harga sehingga harga jual akhir mendekati biaya marjinalnyal Karena produk telekomunikasi terlihat sama, pelanggan telekomunikasi akan memilih produk dengan harga paling murah.

Namun jika derajat substitusi kecil, harga jasa telekomunikasi akan lebih tinggi dari biaya marginalnya. Pelanggan melihat produk telekomunikasi tiap perusahaan memiliki keunikan tersendiri dan akan memilih sesuai dengan preferensinya. Hal ini memunculkan pasar monopoli untuk tiap perusahaan dan merupakan kesempatan bagi perusahaan untuk menentukan harga produk akhir lebih tinggi daripada biaya marjinalnya. Dalam kenyataannya, produk layanan telekomunikasi masingmasing perusahaan mirip satu sama lain namun tidak memicu perang hargal $\mathrm{Hal}$ yang tampaknya kontradiktif ini dapat diselesaikan dengan mengasumsikan bahwa pelanggan akan memilih operator terdekat dalam rangka mengurangi ongkos transaksinya. IUntuk kasus telepun seluler, pelanggan memilih operator yang memberikan kenyamanan lebih seperti operator pilihan rekan-rekannya atau kemudahan berhubungan dengan operator.

Pengaruh kedua pada penentuan harga produk akhir adalah tarif interkoneksi. Secara alamiah, perusahaan tele-

\footnotetext{
${ }^{3}$ Derajat substitusi besar berarti produk perusahaan A dapat dengan mudah digantikan oleh produk perusahaan B karena sangat mirip.

4 Tambahan biaya diakibatkan seorang pelanggan menambah beban ongkos karena menggunakan jasa telekomunikasi

5 Faulhaber dan Hogendorn (2000), Nunn dan Sarvary (2004), Loomis dan Swann (2005)

6 Asumsi ini mengacu pada model Hotelling (1929) tentang pengaruh lokasi terhadap permintaan
}

komunikasi akan menetapkan harga kompetitif kepada pengguna akhir (dalam hal ini pelanggan telepun), namun akan menetapkan tarif interkoneksi bersifat monopoli untuk para pesaing yang menggunakan jaringannya. Harga rendah untuk pengguna akhir tapi tarif interkoneksi tinggi untuk pesaingnya. Namun demikian, dalam persaingan simetris, dimana setiap perusahaan telekomunikasi memiliki kekuatan pasar yang sama dengan pesaingnya, LRT (1998a) berpendapat bahwa harga output dan tarif interkoneksi akan sama untuk setiap perusahaan. Hal itu disebabkan oleh adanya dorongan bagi perusahaan telekomunikasi untuk melakukan tacit collusion Disadari oleh para operator akan adanya tindakan pembalasan (retaliation) dari pesaingnya jika menentukan tarif terlalu tinggi dan juga akan mengurangi laba operator jika menghadapi tarif interkoneksi yang tinggi. Akibatnya tarif interkoneksi seragam namun tidak serta merta rendah. Dengan seragamnya tarif interkoneksi, ruang memperbesar keuntungan menjadi lebih sempit yaitu melalui pasar pengguna akhir.

Ada dua alternatif strategi utama yang bisa dilakukan pada pasar pengguna akhir, strategi Cournot (strategi kuantitatif) dan strategi Bertrand (strategi harga). Strategi Cournot dalam arti luas adalah menguasai pasar dengan produk sebagai alat utamanya. Penguasaan jalur distribusi menjadi tema utama dari strategi Cournot dengan didukung oleh penguasaan selera konsumen melalui penciptaan produk yang disukai. Hanya saja dalam industri telekomunikasi, layanan yang ditawarkan kepada pengguna akhir dapat dikatakan serupa. Meskipun strategi Cournot digunakan, peningkatan kuantitatif layanan kepada pengguna akhir akan lebih

\footnotetext{
7 Kolusi tanpa perjanjian atau kolusi yang terjadi begitu saja tanpa perlu membicarakannya. Juga bisa disebut kolusi tahu sama tahu (Carlton dan Perloff, 2004)
} 
efektif jika perusahaan menurunkan harga jualnya.

Menurut Armstrong (1998), menurunkan harga jual pada konsumen akan berdampak dua hal yaitu akan memikat pelanggan operator lain untuk pindah operator yang menurunkan harga dan meningkatkan kuantitas penjualannya. Konsekuensinya adalah munculnya persaingan Bertrand Persaingan Bertrand membawa konsekwensi pada penurunan laba secara signifikan karena harga dapat turun mendekati biaya marjinalnya. Hal ini menyebabkan secara diam-diam para operator akan berkolusi dan menentukan tarif yang seragam dalam rangka menghindari perang harga, termasuk juga tarif interkoneksi. Hanya saja, kolusi jenis ini tidak menjamin adanya harga jual konsumen yang rendah, karena kolusi dapat saja menentukan tarif yang menjamin laba yang maksimum secara monopoli sehingga harga akhir tetap menjadi terlalu tinggi. Penyeragaman dua harga pada tarif interkoneksi dan harga jual layanan kepada pengguna akhir merupakan kombinasi sempurna untuk menegakkan monopoli pada pasar jasa telekomunikasi.

Alternatif lain dari penentuan harga telekomunikasi adalah penentuan harga non linier. Non linier berarti tarif yang diberlakukan memakai two-part tariff atau multi-part tariff. LRT (1998a) memodelkan penentuan tarif tersebut dengan memfokuskan pada two-part tarif 9 untuk jasa akhir kepada konsumen. Berdasarkan model yang disusun LRT (1998a) berkesimpulan bahwa model two-part tariff akan mencapai hasil yang paling optimum

\footnotetext{
8 Model Bertrand menjelaskan dampak dari persaingan harga dalam sebuah pasar dan merupakan alternatif model selain model Cournot (Nadav dan Piliouras, 2010)

9 Model two-part tariff adalah model penentuan harga dua bagian dimana bagian pertama adalah coverage charge yang tidak terkait dengan jumlah konsumsi $(F)$ dan normal charge yang terkait dengan jumlah konsumsi $(p) . T=F+p q$
}

dalam hal kesejahteraan. Hal itu disebabkan oleh optimalnya harga total yang dibebankan ke konsumen akhir yang terdiri dari harga variabel $(p)$ yang sama dengan biaya marginal khusus perusahaan (termasuk fee interkoneksi) dan harga tetap $(F)$ yang disamakan dengan biaya marginal bertambahnya satu pelanggan plus markup yang merefleksikan derajat substitusi. Dengan memasukkan tarif interkoneksi pada harga variabel $(p)$, maka besaran tarif interkoneksi tergantung dari derajat persaingan jasa telekomunikasi di pasar pengguna akhir. Jika pasarnya kompetitif, maka tarif interkoneksi juga akan rendah seiring dengan rendahnya harga layanan akhir. Perusahaan akan dipaksa untuk menentukan fee interkoneksi sama dengan biaya marjinal interkoneksi. Jika ada perbedaan ongkos biaya marjinal interkoneksi di antara perusahaan, maka perusahaan yang lebih tinggi biaya marjinal interkoneksinya dibanding pesaingnya akan berupaya menurunkan biaya tersebut. Sedangkan harga tetap $(F)$ digunakan untuk menutupi biaya tetap dan menambah keuntungan perusahaan. Hasil akhir dari penentuan harga non linier adalah harga layanan rendah dan perusahaan tetap mendapatkan laba.

Tentunya kesimpulan ini menggembirakan jika dikaitkan dengan model linier dimana justru harga akhir yang dipengaruhi oleh fee interkoneksi menghasilkan tindakan kolusi. Dengan mempraktikkan harga non linier maka kolusi dapat terhindarkan dan persaingan yang membawa kepada kesejahteraan masyarakat yang lebih besar dapat dicapai. Namun demikian, Armstrong (1998) mengingatkan bahwa, hal tersebut dapat tercapai jika asumsi homogenitas konsumen dipenuhi] Jika konsumen heterogen maka harga akhir akan lebih besar dari

\footnotetext{
${ }^{10}$ Heterogenitas konsumen dipengaruhi oleh pola berkomunikasi menggunakan telepun atau ponsel. Setiap jenis pekerjaan ataupun perbedaan pendapatan akan mempengaruhi pola berkomunikasi tersebut.
} 
biaya marginalnya namun perkolusian tetap tidak terjadi (Dessein, 2003). Pada kenyataannya di kebanyakan wilayah para konsumen adalah heterogen, kecuali pada kota-kota kecil ataupun di pedesaan. Padahal kebanyakan pengguna jasa telekomunikasi lebih banyak tinggal di kota yang lebih heterogen penduduknya.

\section{PENENTUAN HARGA INTERKONEKSI DALAM PERSAINGAN ASIMETRIS}

Penentuan tarif interkoneksi dalam persaingan asimatris terjadi ketika di dalam pasar terdapat dua jenis operator yaitu operator lama (incumbent) dan operator baru (entrants). Incumbent sebelumnya telah menikmati monopoli yang diberikan pemerintah sebelumnya.Diberikannya hak monopoli karena dianggap bisnis telekomunikasi dikategorikan sebagai barang yang secara alamiah harus dimonopoli (natural monopoly). Namun, hak itu telah ditiadakan menyusul berbagai studi tentang kelayakan industri telekomunikasi berstatus natural monopoly 1 Investasi besar mereka telah tertanam sejak lama dan mengklaim kalau belum impas. Karena telah lama menguasai pasar maka incumbent memiliki keunggulan dibanding pesaingnya yaitu pengetahuan tentang pasar dan permodalan yang lebih baik karena investasi awal sudah kembali.

Tentunya akan terjadi persaingan tidak seimbang antara incumbent dan entrants karena biaya produksi incumbent sudah mencapai skala ekonomisnya sedangkan entrants baru mulai menjalankan bisnisnya. Dalam memenangkan persaingan ini, incumbent menggunakan dua tahap strategi (two stage game). Tahap pertama adalah menentukan berapa fee interkoneksi, lalu pada tahap kedua

\footnotetext{
11Pencabutan status natural monopoly industry pada industri telekomunikasi diputuskan oleh hakim Harold Green pada 1982, pada industri telekomunikasi Amerika Serikat (Huber, 1993). Studi yang mendukung antara lain Fuss dan Waverman (1981), Phillips (1972), dan Hutton (1981).
}

menentukan harga jual kepada pengguna akhir. Secara intuitif para incumbent akan menentukan harga akhir yang rendah dan fee interkoneksi yang tinggi. Hal ini ditujukan untuk mengeliminasi para pesaingnya agar kekuasaan monopoli kembali ke incumbent.

Ada dua alternatif jalan keluar bagi entrants yaitu bernegosiasi soal tarif interkoneksi dengan incumbent atau minta pertolongan pemerintah dalam menentukan tarif interkoneksi. Pilihan pertama sangat tergantung pada kemauan incumbent untuk bernegosiasi. Sulitnya bagi incumbent, penolakan bernegosiasi akan menarik perhatian komisi anti monopoli. Namun menerima negosiasi dapat berarti dua hal yaitu membantu membesarkan pesaingnya atau sebagai titik tolak menuju persengkongkolan membangun kekuatan monopoli baru. Jika negosiasi berhasil, entrants punya kesempatan menanamkan investasi besar dalam rangka mengejar ketertinggalan dari incumbent. Hal ini tentu tidak disukai oleh incumbent tapi bermanfaat bagi peningkatan kesejahteraan masyarakat. Lebih jauh lagi, negosiasi dapat pula menghasilkan kartel telekomunikasi yang akhirnya dapat menurunkan kesejahteraan masyarakat2 Kartel dapat dilakukan melalui pembagian wilayah dimana daerah operasional incumbent tidak meliputi area tertentu yang akan dikuasai entrants (LRT, 1998a).

Untuk penentuan harga non linier (two part tariff) pada persaingan asimetris memiliki bahasan lain yang menarik. Incumbent akan menentukan fee interkoneksi serendah biaya marjinalnya karena menghindari masalah double marginalization 3 Entrants akan menentukan

\footnotetext{
12Penurunan kesejahteraan diakibatkan oleh tingginya harga jual, keterbatasan ketersediaan layanan, jeleknya kualitas layanan, dan adanya dead weight loss (Bergson, 1973)

${ }^{13}$ Double marginalization terjadi ketika perusahaan pemasok input (A) dan perusahaan hilir (B) menetapkan harga jual $\mathrm{MR}=\mathrm{MC}$. Konsumen akhir menanggung inefisiensi ganda yang berasal dari A dan B. Jika B mengakuisisi A, akan lebih
} 
tarif interkoneksi lebih besar daripada tarif incumbent dan menentukan harga layanan kepada pengguna akhir yang tidak lebih rendah dari incumbent. Bagi incumbent akan mengalami defisit biaya interkoneksi tapi mendapatkan lebih banyak pelanggan. Bagi entrants, mengalami defisit pelanggan tapi mendapatkan pendapatan lebih dari tarif interkoneksi. Bagi keduanya, defisit dari hubungan ini akan menguntungkan kedua belah pihak. Pihak entrants mendapatkan surplus dari perbedaan tarif interkoneksi dan pihak incumbent mendapatkan surplus dari pengguna akhir. Adanya unsur $F$ dalam two part tariff dapat digunakan untuk menutupi kerugian yang berasal dari unsur $p q$. Namun bagi konsumen, hal ini berpengaruh negatif kesejahteraan karena harga akhir yang tidak rendah mengurangi surplus konsumen (Carter dan Wright, 2003).

\section{CAMPUR TANGAN PEMERINTAH}

Permasalahan dalam fee interkoneksi berdampak panjang pada persaingan layanan telekomunikasi. Di samping dapat mempengaruhi harga akhir layanan telekomunikasi juga merupakan alat ampuh perusahaan untuk mengurangi tensi persaingan. Dalam persaingan yang simetris dengan penentuan harga yang linier, perkolusian antar perusahaan telekomunikasi yang melahirkan kartel adalah logis dapat terjadi. Hal ini tentu akan merugikan masyarakat karena diduga kartel akan menentukan harga layanan akhir yang menjauhi biaya marjinalnya. Menurut Carter dan Wright (1999), negosiasi pada penentuan tarif interkoneksi antar perusahaan telekomunikasi yang membawa pada perkolusian seharusnya dihentikan dan diganti dengan regulasi dari pemerintah yang menentukan tarif tersebut sebesar biaya marjinalnya. Regulasi pemerintah diperlukan agar pasar terhindar

efisien bagi perusahaan dan masyarakat jika B menetapkan harga input dari A sebesar biaya marjinalnya (Carlton dan Perloff, 2006) dari eksploitasi monopoli karena perkolusian para operator. Namun untuk pasar jasa akhir tetap dibiarkan kompetitif. Kelemahan dari cara ini adalah pengetahuan pemerintah pada informasi biaya marjinal lebih terbatas dibanding perusahaan. Perlu usaha tambahan dan biaya lebih besar untuk mengetahui besarnya biaya marjinal interkoneksi yang sebenarnya. Risiko yang dihadapi pemerintah cukup besar. Jika menentukan tarif interkoneksi terlalu kecil, perusahaan yang kurang efisien akan keluar dan jumlah perusahaan dalam industri telekomunikasi mengecil dan cenderung lebih mudah tergoda melakukan kolusi. Jika menentukan tarif interkoneksi terlalu besar, pelanggan akan dibebankan harga layanan telekomunikasi yang mahal dan berdampak mengurangi surplus konsumennya.

Di sisi lain, jika harga layanan akhir ditentukan berdasarkan two part tariff, konsekwensinya dapat berbeda. Secara intuitif, para pelaku layanan telekomunikasi akan bersaing satu sama lain. Pemerintah tidak perlu turut campur dalam kondisi ini karena perusahaan secara alamiah akan bersaing dan menentukan tarif interkoneksi yang rendah dan seragam. Tindakan campur tangan pemerintah berupa pelarangan kolusi maupun penentuan tarif interkoneksi adalah tindakan sia-sia karena perusahaan tanpa perlu diatur sudah melakukannya sendiri.

Jika industri telekomunikasi dihadapkan pada persaingan yang asimetris, dominasi incumbent pada industri telekomunikasi dapat mengusir entrants dari pasar. Menurut Armstrong (1998) serta Carter dan Wright (1999), tanpa campur tangan pemerintah dominasi incumbent semakin kokoh karena para konsumen biasanya tetap memilih incumbent sebagai penyedia jasa. Tentunya semakin lama pangsa pasar entrants akan punah. Meskipun masih punya peluang bertahan dan bahkan berkembang jika negosiasi fee interkoneksi dengan incumbent berhasil tetapi peluang terusir dari pasar lebih besar. 
Hal itu karena entrants akan berusaha untuk menerima kondisi defisit dari interkoneksitas dimana pengeluaran interkoneksitas entrants lebih besar dari pemasukan interkoneksitas. Jika ini diteruskan akan mengurangi keuntungan atau bahkan kerugian sehingga memaksa entrants menaikkan harga akhir. Akibatnya volume jasa menjadi berkurang dan bahkan berkurang pula pelanggannya. Carter dan Wright (1999) telah menghitung jika kondisi ini dibiarkan dalam persaingan tanpa campur tangan pemerintah maka kesejahteraan total akan sangat rendah dibanding jika pemerintah menentukan tarif interkoneksi yang rendah. Oleh sebab itu, campur tangan pemerintah tetap harus dilakukan melalui regulasi penentuan fee interkoneksi yang mendekati biaya marjinalnya.

Kisah persaingan antara incumbent dan entrants akan berbeda jika harga layanan pada pengguna akhir menggunakan two part tariff. Kedua pihak akan menerima penentuan harga ini. Namun pemerintah harus mencegah praktik ini karena menjadi kolusi terselubung atau bahkan terjadi tacit collusion dalam rangka memonopoli pasar telekomunikasi. Kesejahteraan konsumen akhir akan berkurang dan efisiensi produksi menjadi rendah.

\section{KESIMPULAN}

Penentuan harga interkoneksi antar perusahaan layanan telekomunikasi sangat mempengaruhi harga akhir dari jasa telekomunikasi pada pengguna akhir, kecuali pada kasus harga non linier pada persaingan yang simetris. Pada penentuan harga linier pada persaingan simetris, ancaman kolusi antar perusahaan sangatlah logis dapat terjadi karena lebih menguntungkan bagi perusahaan. Pada persaingan yang asimetris baik untuk penentuan harga linier maupun non linier, ancaman adanya predatory pricing dari incumbent akan menyebabkan munculnya pasar monopoli baru, setelah sebelumnya hak monopoli tersebut dihapus peme-rintah dengan membuka kesempatan bagi perusahaanperusahaan telekomunikasi (operatoroperator telekomunikasi) baru untuk menikmati pasar telekomunikasi. Tampak sekali bahwa campur tangan pemerintah sangat diperlukan dalam bisnis telekomunikasi dan tidak lagi menganggap bahwa produk-produk tele-komunikasi adalah natural monopoly. Campur tangan pemerintah diperlukan untuk menentukan tarif interkoneksi antar perusahaan telekomunikasi yang men-dekati biaya marginal. Meskipun penen-tuan harga non linier pada persaingan simetris dapat mencegah campur pe-merintah dalam penentuan tarif inter-koneksi antar perusahaan (operator), namun jika konsumen tidak homogen maka campur tangan pemerintah terpaksa dilakukan.

Bagi pemerintah, campur tangan sebaiknya dilakukan pada jasa telekomunikasi yang persaingannya adalah asimetris dan hanya pada bagian tarif interkoneksi antar operator saja. Hal itu agar kondisi persaingan tetap terjaga dan kemakmuran total menjadi maksimal. Namun jika pasar yang dihadapi adalah pasar dengan persaingan simetris maka sebaiknya pemerintah mendorong industri untuk menerapkan penentuan harga yang non linier agar tidak perlu campur tangan pemerintah. Mengapa demikian? Karena campur tangan pemerintah mengandung konsekwensi yang tidak mudah yaitu pemerintah harus tahu persis berapa biaya marginal dalam menambah satu panggilan komunikasi dalam interkoneksi antar operator. Hal ini bukanlah perkara mudah karena para operator berusaha menyembunyikan informasi ini sehingga pemerintah diharapkan salah menentukan tarif yang sesuai dengan kemauan operator. 


\section{DAFTAR PUSTAKA}

Armstrong, M., (1998), "Network Interconnection Telecommunication", The Economic Journal, 108 (May), pp. 545 - 564.

Bergson, Abram, (1973), “On Monopoly Welfare Loss”, The American Economic Review, vol. 63, issue 5, December, pp. 853-870.

Carter, M, dan J. Wright, (1999), "Interconnection in Network Industries", Reviews of Industrial Organization, 14, pp. 1-25.

Carter, M, dan J. Wright, (2003), “Asymmetric Network Interconnection”, Reviews of Industrial Organization, 22, pp. 27-46.

Carlton, Dennis W, and Jeffrey M Perloff, (2006), Modern Industrial Organization, $4^{\text {th }}$ ed., Prentice Hall.

Dessein, W, (2003), "Network Competition in Nonlinear Pricing", RAND Journal of Economics, vol. 34, no. 4, pp. 593-611.

Faulhaber, GR, and C Hogendorn, (2000), “The Market Structure of Broadband Telecommunications", Journal of Industrial Economics, vol 48, no 3, pp. 305-329.

Fuss, MA and L. Waverman, (1981), "Regulation and the Multiproduct Firm: The Case of Telecommunications in Canada", dalam Studies in Public Regulation (editor: Gary Fromm), NBER, pp. 277-328.

Hotelling, (1929), "Stability in Competition", The Economic Journal, vol 39, no. 153, March, pp. 41-57.

Huber, Peter W, (1993), "Telephones, Competition, and the Candice Coated Monopoly", Regulation, no. 3, Cato Review Of Business \& Government, pp. 34-43.

Hutton, TJ, (1981), “The Proposed Deregulation of Domestic Common Carrier Telecommunications", California Law Review, vol. 69, pp. 455-469.

Laffont, J-J, P. Rey, dan J. Tirole, (1998a), “Network Competition: I. Overview And Nondiscriminatory Pricing", RAND Journal of Economics, vol 29, no. 1. pp. 1-37

Laffont, J-J, P. Rey, dan J. Tirole, (1998b), “Network Competition: II. Price Discrimination", RAND Journal of Economics, vol 29, no. 1. pp. 38-56.

Loomis, David G, and Christopher M. Swann, (2005), "Intermodal competition in local telecommunications markets", Information Economics and Policy, 17, pp. 97-113.

Nadav, U dan G Piliouras, (2010), "No Regret Learning in Oligopolies: Cournot vs Bertrand", Algorithmic Game Theory, vol 6386, pp. 300-311.

Nunn, Dana and Miklos Sarvary, (2004), "Pricing Practices and Firms' Market Power in International Cellular Markets, An Empirical Study", International Journal of Research Marketing, vol. 21, issue 4, December, pp. 377-395.

Phillips, CF, (1972), "Domestic Telecommunications Policy: An Overview", Washington And Lee Law Review", Vol XXIX, pp. 235-252.

Shy,Oz, (2001), The Economics of Network Industries, Cambridge University Press. 